\title{
The need to invest in pandemic preparedness: COVID-19 is not the first pandemic, nor will it be the last
}

The 1918 influenza pandemic infected one-third of the world's population. It is believed that 50 million people died. At that time, the world's population was less than 2 billion. This was in the era before intercontinental air travel and globalisation. The 1900s witnessed two more worldwide influenza outbreaks, the 1957 H2N2 Asian flu and 1968 H3N2 Hong Kong flu, with deaths ranging between 1 and 3 million. The first pandemic of the 21st century was in 2009, with the first cases of the novel swine-derived H1N1 influenza, a virus detected in Mexico and the USA in April 2009. By the end of that year, H1N1 had spread to 208 countries, with hundreds of thousands infected and around 18000 deaths. H1N1 was evidence that continuous global movement would not allow for local eradication, but would facilitate accelerated global spread of a new killer virus. ${ }^{[1]}$

On 30 January 2020, the World Health Organization (WHO) declared the novel coronavirus outbreak a public health emergency of international concern, and on 11 February 2020, they announced a name for the new coronavirus disease: COVID-19. ${ }^{[2]}$ In Africa, on 14 February, Egypt was the first country to record a COVID-19 patient. ${ }^{[3]}$ South Africa recorded its first patient on 5 March. ${ }^{[4]}$ As of 24 June 2020, there were 9129146 people infected, and 473797 deaths globally. ${ }^{[5]}$

Rapidly spreading infectious outbreaks have plagued the first two decades of the 21 st century. Severe acute respiratory syndrome (SARS) infected 8098 people and killed 774 victims early in the new millennium. ${ }^{[1]}$ During the Ebola virus epidemic between December 2013 and April 2016, there were more than 28616 people infected, and 11310 deaths in Guinea, Liberia and Sierra Leone. ${ }^{[1]}$ By 2017, 690 had already succumbed to Middle East respiratory syndrome (MERS), and Zika had infected over 1 million people in the Americas. ${ }^{[1]}$

The International Working Group on Financing Preparedness, in its 2017 report, ${ }^{[1]}$ cites the reasons for the frequency and diversity of disease outbreaks increasing steadily since 1980 as follows: 'First, recent advances in travel, trade and connectivity have led to rapid increases in speed and volume not only of humans, animals and commodities, but also of deadly pathogens. Second, there has been unprecedented increase in unplanned urbanisation, because of which millions of people live in crowded spaces and unhygienic conditions, which can be perfect breeding grounds for diseases to spread. Third, civil unrest and war displace large volumes of people, who move to new places, carrying with them a variety of infectious disease organisms. And fourth, global warming is creating new belts of warm and moist environments, which are ideal conditions for the spread of disease vectors. ${ }^{[}[1]$

Human tragedy from rapidly spreading infectious outbreaks is profound, with extensive bearing on the health, economic and social sectors. Pandemic costs can be measured by monumental human suffering as a result of the accompanying health, economic and social disruptions. The painful statistic of lives lost is only the first measure of impact. Economic and social disruptions, sometimes of titanic proportions, lead to undermining of communities and governance. ${ }^{[1]}$ As the COVID-19 pandemic evolves, it is becoming clear that it will be with us for around 2 years, or longer. With the increasing frequency of pandemics, we will probably see another one soon after. Therefore investing in pandemic preparedness and response nationally, regionally and globally is critical. Our lived experiences and the many lives lost so early in COVID-19 are evidence that the costs of inaction when it comes to prioritisation and preparedness are immense. As the world starts the recovery phase from the calamity, the pandemic disaster should not ebb like a receding memory, and preparedness initiatives should not be overlooked in favour of other activities until the next outbreak emerges, as has happened thus far. ${ }^{[1]}$

COVID-19, like the 1918 influenza plague, has underscored how vulnerable the world is. It has also highlighted all people's universal vulnerability. Human vulnerability is understood as a spectrum, with one end being all human life conditioned by vulnerability because of our 'embodied, finite and socially contingent existence, ${ }^{\left[{ }^{[6]}\right.}$ while at the other end of the spectrum, the term denotes more than the universal vulnerability of humanity. People vary in their exposure to risk, and in their abilities and resources to counter such risk. It is to these people with greater exposure to risk and decreased resources to counter it that greater duties of justice are owed, and specific moral obligations are required. Hence, many vulnerabilities move beyond the universal and are context dependent, and warrant ethical responses as a result of their significance within particular settings. ${ }^{[7]}$ For many, contextual vulnerability may manifest only after a pandemic has set in and measures for containment are instituted. COVID-19 containment has resulted in millions of people losing their livelihoods. Moreover, $\mathrm{UNESCO}^{[8]}$ draws attention to the fact that vulnerable individuals become even more vulnerable in times of pandemic, and in particular where the vulnerability is related to poverty, discrimination, gender, illness, loss of autonomy or functionality, older age, disability, ethnicity, incarceration, undocumented migration and the status of refugees and stateless persons. Isolation and quarantine could impact negatively on intra-familial violence, and on people living in unstable economic situations. Moreover, psychological stress could be triggered by pandemic anxiety and confinement. Vulnerability in itself is reason enough to require preparedness for pandemics. Responding to outbreaks 'on the run' costs far more in terms of lives, money and social harms. 
Preparedness for pandemics would be a co-benefit for the healthcare sector: for example, surveillance and diagnostic capacities could be used for routine patient care. In the healthcare sector, this preparedness would mean investing in health systems geared towards universal health security. ${ }^{[1]}$ Health security refers to protecting people from threats to their health, i.e. the intrinsic value of protection against risk. Universal health security requires that everybody is protected from threats to their health, and it includes reducing the vulnerability of populations to threats of infectious outbreaks within and across national borders. During outbreaks, genuine health security can only be achieved if everyone is protected. Achieving universal health security would be a substantive move towards universal health coverage, and should be integrated into the planning of resilient health systems ${ }^{[1]}$ We are witness to the huge pressure our health systems have come under during the current pandemic, with non-COVID-19 healthcare severely compromised as resources have been diverted to pandemic containment, and seen that the fear factor has resulted in patients avoiding seeking care.

As responsible global citizens, we should not allow the cycle of panic and neglect ${ }^{[1]}$ to continue as it has done during pandemics of the past. Collective action towards preparedness for the next pandemic is essential. COVID-19 is not the first pandemic, and neither will it be the last. Investing in pandemic preparedness will go a long way towards avoiding human suffering, protecting lives and safeguarding livelihoods.

\section{Ames Dhai}

Editor

ames.dhai@wits.ac.za

S Afr J Bioethics Law 2020;13(1):3-4. https://doi.org/10.7196/SAJBL.2020. v13i1.737

1. International Working Group on Financing Preparedness. From Panic and Neglect to Investing in Health Security: Financing Pandemic Preparedness at a National Level. Washington, DC: World Bank, 2017. https://openknowledge.worldbank. org/bitstream/handle/10986/26761/115271-WP-PUBLIC-IWG-FINAL-versionembargoed.pdf?sequence $=1$ (accessed 23 June 2020).

2. World Health Organization. Rolling updates on coronavirus disease (COVID-19). https://www.who.int/emergencies/diseases/novel-coronavirus-2019/events-asthey-happen. Geneva: WHO, 2020 (accessed 23 June 2020).

3. Worldometer. Coronavirus. https://www.worldometers.info/coronavirus/country/ egypt/ (accessed 24 June 2020).

4. National Institute of Communicable Diseases. First case of COVID-19 coronavirus reported in SA. Pretoria: NICD, 2020. https://www.nicd.ac.za/first-case-of-covid19-coronavirus-reported-in-sa/ (accessed 24 June 2020).

5. World Health Organization. WHO Corona Virus Disease (COVID-19) Dashboard. Geneva: WHO, 2020. https://covid19.who.int/?gclid=EAlalQobChMI0Zfm46ab6gl VDe3tCh1Qig7yEAAYASAAEgKKDvD BwE (accessed 24 June 2020).

6. Rogers W, Mackenzie C, Dodds S. Why bioethics needs a concept of vulnerability. Int J Feminist Approaches Bioethics 2012; 5(2):11-38. https://doi.org/10.3138/ijfab.5.2.11

7. Rendtorff JD. Basic ethical principles in European bioethics and biolaw: Autonomy, dignity, integrity and vulnerability - towards a foundation of bioethics and biolaw. Med Healthcare Philos 2002;5:235-244.

8. United Nations Educational, Scientific and Cultural Organisation. Statement on COVID-19: Ethical Considerations from a Global Perspective. Paris: UNESCO, 26 March 2020. https://unesdoc.unesco.org/ark:/48223/pf0000373115 (accessed 24 June 2020). 